Takae Ibuki MD PhD, Noriomi Ando MD, Yoshifumi Tanaka MD PhD

\title{
Vocal cord paralysis associated with difficult gastric tube insertion
}

Many clinical reports have described vocal cord paralysis after general anaesthesia. In most cases, paralysis was attributed to tracheal tube insertion. In this report we describe one patient in whom gastric tube insertion was strongly suspected as the cause of paralysis. The patient was a 47-yr-old man who underwent left hepatic lobectomy. Just after the operation he complained of hoarseness and a diagnosis of complete right vocal cord paralysis was made, from which he recovered after eight weeks. In this patient, insertion of the gastric tube seemed to have injured the anterior ramus of the right recurrent laryngeal nerve directly. Although there have been several reports of vocal cord paralysis induced by gastric tubes, none has noted such an acute onset and direct nerve injury. Therefore we would like to report this rare case and elucidate the mechanism of vocal cord paralysis. Careful attention should be paid in inserting a gastric tube to patients under general anaesthesia and, sometimes, the use of the soft tube may be indicated.

Plusieurs publications portent sur la paralysie des cordes vocales après une anesthésie générale. Dans la plupart des cas, on attribue la paralysie à l'insertion du tube endotrachéal. Ce compte-rendu se rapporte à un cas où linsertion d'une sonde gastrique est fortement mise en cause dans létiologie de la paralysie. Un patient de 47 ans subit une hépatectomie. Immédiatement après lïntervention, il se plaint de raucité de la voix et une paralysie de la corde vocale droite est diagnostiquée. La récupération s'effectue en huit semaines. Chez ce patient,

\section{Key words}

COMPLICATIONS: vocal cord paralysis;

LARYNX: vocal cords.

From the Department of Anesthesiology, Kyoto Prefectural University of Medicine.

Address correspondence to: Dr. T. Ibuki, Department of Anesthesiology, Kyoto Prefectural University of Medicine, Kawaramachi Hirokoji, Kamigyo-ku, Kyoto, 602 Japan.

Present address: Dr. Ibuki, c/o Prof. George D. Pappas, University of Illinois at Chicago, Department of Anatomy and Cell Biology, 808 S. Wood St.-578 CME (M/C 512), Chicago, IL 60612 USA.

Accepted for publication 29th January, 1994. la sonde gastrique semble avoir endommagé directement le rameau antérieur du nerf récurrent laryngé. Bien que plusieurs observations identiques de paralysie des cordes vocales provoquée par une sonde gastrique aient été publiées, aucune ne rapporte un début aussi soudain avec lésion nerveuse directe. Nous décrivons ici ce cas rare et tenterons d'expliquer le mécanisme de la paralyse de la corde vocale. Il faut être très prudent lorsquion insère un tube gastrique sous anesthésie générale et il est parfois préférable d'utiliser un tube mou.

Nasogastric tubes, which are widely used in patients with intra-abdominal disease, can be useful in patients during general anaesthesia to prevent complications associated with gastric retention. Under general anaesthesia a gastric tube is inserted without the cooperation of the patient, who cannot swallow it. Only a few reports have described vocal cord paralysis caused by nasogastric tubes, but in all cases paralysis took at least three days to develop, and was due to inflammation around the nerve. ${ }^{1-3}$

In this case, a recurrent laryngeal nerve palsy occurred immediately after general anaesthesia for abdominal surgery in a patient with no previous laryngeal symptoms. A tracheal tube and a gastric tube had been inserted during surgery but direct injury to the right recurrent laryngeal nerve by inserting the nasogastric tube is strongly suspected as the cause.

The purpose of this paper is to elucidate the mechanism of right recurrent laryngeal nerve paralysis and to recommend the use of a soft nasogastric tube when insertion is difficult.

\section{Case report}

A 47-yr-old man with hepatocellular carcinoma was admitted for further examination and surgery. His medical history included appendicitis at the age of $25 \mathrm{yr}$, hepatitis $B$ at the age of $44 \mathrm{yr}$, and a traffic accident at the age of $46 \mathrm{yr}$. He had no history of blood transfusion. Left hepatic lobectomy was planned.

Preoperative routine tests were normal except for ICG retention of $18.9 \%$ in $15 \mathrm{~min}$, AST of $33 \mathrm{IU} \cdot \mathrm{L}^{-1}$, and ALT of $44 \mathrm{IU} \cdot \mathrm{L}^{-1}$. Other routine examinations, including ECG and pulmonary function tests were normal.

Atropine sulphate $0.5 \mathrm{mg}$, hydroxyzine $50 \mathrm{mg}$, and 
ranitidine $50 \mathrm{mg}$ im were given as premedication. General anaesthesia was induced, $30 \mathrm{~min}$ later, with thiopentone $250 \mathrm{mg}$ and maintained with isoflurane and nitrous oxide. Tracheal intubation was performed, after succinylcholine $80 \mathrm{mg}$, easily and atraumatically with an endotracheal tube of $8.5 \mathrm{~mm}$ inner diameter (Malinkhrot Co., Ltd). The cuff was ascertained to be in the trachea beyond the vocal cords and was inflated with a small amount of air. Insertion of the gastric tube (TONOMITOR; gastric catheter for the measurement of intramucosal $\mathrm{pH}$, Tonometrics Co., Ltd. USA) was extremely difficult, and took three anaesthetists more than $40 \mathrm{~min}$. A small amount of bleeding was observed during insertion of the gastric tube through the nasal cavity. The patient tolerated the operation well and returned to the ward in good condition after tracheal extubation. The operative time was $4 \mathrm{hr} 40 \mathrm{~min}$ and the anaesthesia time was eight hours.

This time discrepancy between the operative time and the anaesthesia time was caused by the insertion of a thermodilution catheter for cardiac monitoring, IVH (intravenous hyperelimination) catheter for postoperative management and by the decrease of the body temperature.

The postoperative course was uneventful except for hoarseness of which the patient complained just after surgery. Examination of the right vocal cord found it to be fixed in the paramedian position: complete right vocal cord paralysis was diagnosed. Steroids, vitamin B12, and ATP were administered without effect. Hoarseness, which was extremely severe, was the patient's most serious postoperative problem since his business was carried out via telephone. Thirty days after operation he was discharged from hospital, and by four weeks his voice had recovered almost completely.

\section{Discussion}

The mechanism of recurrent laryngeal nerve paralysis after general anaesthesia has been discussed in many previous case reports.

\section{Position of neck}

Recurrent laryngeal nerve paralysis can be induced by compression, traction, or other injury. There have been reports of paralysis after laryngoscopic examination ${ }^{4}$ or neck overextension as in orthopaedic therapy. ${ }^{5}$ Because the recurrent laryngeal nerve, especially the left, ascends deeply in the tracheoesophageal groove from the thoracic cavity, it can be compressed by an endotracheal tube or cuff if the trachea or the neck is rotated. ${ }^{6}$ It has been proposed that overextension of the neck during tracheal intubation or an unnatural position of the head and neck occurring during surgery can cause traction of the re- current laryngeal nerve from the mediastinum and vocal cord paralysis. ${ }^{7}$ Overextension, flexion, or rotation of the neck during tracheal intubation or operation was not observed in our case.

\section{Inappropriate-sized endotracheal tube and cuff problems}

Paralysis has been attributed to compression of the recurrent laryngeal nerve by an inappropriately-sized endotracheal tube or over-inflated cuff. ${ }^{8-12}$ The pathological change in the nerve is neither neurotemesis nor axonotemesis but neuropraxia, induced by temporary impairment of the excitation conduction system based on peripheral circulatory disorders. Some reports have shown ${ }^{8,9}$ that the anterior branch of the recurrent laryngeal nerve could be compressed between the cuff and the thyroid lamina when the cuff was inflated within the larynx. Dobrin and Canfield measured the pressure exerted by inflated endotracheal tube cuffs against the tracheal mucosa and determined the effect of mucosal pressure on tracheal wall blood flow. ${ }^{11}$ They compared the mucosal pressures generated by 18 brands of endotracheal tubes and concluded that compliant cuffs were preferable to stiff cuffs because they caused less ischaemia: no correlation was found between the incidence of laryngeal nerve palsy caused by endotracheal tubes and the duration of intubation. ${ }^{8}$ In our case an endotracheal tube with a lowpressure, compliant cuff was used; the tube size was appropriate ( $8.5 \mathrm{~mm}$ in diameter), intubation was performed very smoothly and atraumatically, and cuff pressure was checked carefully during the operation.

\section{Effect of ethylene oxide gas}

Ethylene oxide gas (EOG), widely used for sterilization of medical materials such as endotracheal tubes, can cause chemical burns and ulceration of the skin and $\mathrm{mu}-$ cous membranes. Holley and Gildea described one case in which myelin degeneration was seen in the vagus nerve at autopsy and suggested the possibility of gas sterilization as a cause of vocal cord paralysis. ${ }^{13}$ In our case, endotracheal tubes were constructed of PVC (polyvinylchloride) with a latex rubber cuff. All have been sterilized with EOG. Tubes are aerated for 14 days, and the concentration of residual ethylene components is below the permitted level.

\section{Other factors}

Various other factors have been suspected as possible causes of laryngeal nerve paralysis including downward traction of the oesophagus, previously existing assymptomatic palsy, decrease in elasticity of the trachea or surrounding tissues and decrease in the resistance of the re- 
current laryngeal nerve due to aging or many other factors. ${ }^{9,14,15}$ These factors cannot explain completely the mechanism of palsy in our patient.

\section{Nasogastric tubes}

Insertion of the nasogastric tube in this patient was extremely difficult and took three well-trained anaesthetists more than $40 \mathrm{~min}$. Complications associated with the insertion of and placement of nasogastric tubes have been reported. ${ }^{16-21}$ In our review of the literature, the earliest description of cricoid chondritis after nasogastric intubation was by Wangensteen et al. in 1939. ${ }^{16}$ Also in 1939, Iglauer and Molt reported ten cases in which a nasogastric tube could have been the cause of postcricoid ulceration and bilateral vocal cord paralysis. ${ }^{17}$ In 1946 , four cases of laryngeal injury induced by nasogastric tube were added. ${ }^{18}$ Since then, only a few reports have been written. ${ }^{19-23}$ The widespread use of endotracheal tubes transferred the focus of interest to endotracheal tubes. In the 1980s, some case reports, experimental, and prospective studies concerning vocal cord paralysis caused by nasogastric tubes or oesophageal stethoscopes were presented. ${ }^{1-3}$ In the reports, the onset of symptoms, which all included hoarseness, was later than that caused by endotracheal tubes.

In the case of endotracheal tubes, according to the analysis of Cavo and Britain, the duration of the procedure was < six hours in most cases. ${ }^{12}$ Brandwein et al., described the immediate onset of symptoms of bilateral vocal cord paralysis induced by endotracheal tubes after extubation in $50 \%$ and within a few hours in all except one patient. ${ }^{24}$

In the case of gastric tubes, the onset of symptoms, which all included hoarseness, was longer; usually occurring more than four days and up to 12 days after operation. ${ }^{1,2}$ The reason for this difference could be that in the case of endotracheal tubes, because the mechanism of paralysis is presumably direct compression of the anterior ramus of the recurrent laryngeal nerve or a temporary and local disturbance of blood flow to the nerve, the time needed for the onset of symptoms is relatively short, while in the case of gastric tubes, the mechanism is thought to be erosion or ulceration of the posterior cricoid plate due to compression by the tube located between the cricoid cartilage and the cervical spine, followed by a diffuse inflammatory process leading to perichondritis, anterior cricoid infection, posterior subglottic stenosis and vocal cord immobility, so a longer time is needed for hoarseness to develop.

In our patient, the onset was immediate, so direct impairment of the nerve would be more likely than an inflammatory process. In fact, the nasogastric tube we used
(TONOMITOR) was harder and less elastic than the normal gastric tubes. The insertion of such a rigid tube in an unconscious patient under general anaesthesia is suspected to have resulted in direct and severe injury of the anterior ramus of the recurrent laryngeal nerve, which would not have occurred in a conscious patient.

Furthermore, Sofferman and Hubbell, and Friedman and Toriumi, describing a patient with vocal cord paralysis caused by an oesophageal stethoscope stated that posterior recurrent laryngeal neuropraxia was the true physiological deficit. ${ }^{1,3}$ The recurrent laryngeal nerve ascends to the larynx from the thorax within the loose connective tissue between the oesophagus and the trachea. The nerve divides into two branches, posterior and anterior rami, either inside or outside the larynx..$^{25}$ Although there are many variations in the level of bifurcation and in the distribution of the nerve, the anterior ramus always contains motor fibres and the posterior ramus sensory fibres. ${ }^{26}$ Therefore, injury of the posterior ramus would hardly cause vocal cord paralysis. In our patient, repeated attempts to insert a rigid nasogastric tube is suspected to have caused direct injury to the anterior ramus of the recurrent laryngeal nerve.

The TONOMITOR, which is used to measure intramucosal $\mathrm{pH}$ in the gastrointestinal tract is much stiffer than a nasogastric tube. If insertion is difficult, the use of a TONOMITOR designed for sigmoid insertion, which is softer than a gastric TONOMITOR should be considered.

\section{Conclusion}

We report a rare case of vocal cord paralysis caused by gastric tube insertion. The mechanism of injury is suspected to have been direct trauma to the anterior ramus of the recurrent laryngeal nerve. When a gastric tube is inserted in unconscious patients, care should be taken to avoid complications. If passage is difficult, the position of the neck may be changed to prevent overextension or rotation of the neck, and the insertion can be sometimes accomplished using Magill forceps under laryngoscopic observation. In more difficult cases the use of a softer tube should be considered.

\section{References}

1 Sofferman RA, Hubbell RN. Laryngeal complications of nasogastric tubes. Ann Otol Rhinol Laryngol 1981; 90 : 465-8.

2 Friedman M, Baim H, Shelton $V$, et al. Laryngeal injuries secondary to nasogastric tubes. Ann Otol Rhinol Laryngol 1981; 90: 469-74.

3 Friedman M, Toriumi DM. Esophageal stethoscope. Arch Otolaryngol Head Neck Surg 1989; 115: 95-8. 
4 Faaborg-Andersen $K$. Recurrent laryngeal paralysis of unknown aetiology. Acta Otolaryngol 1954; 118: 68-75.

5 Kindler $W$. Beitrag zur Entstehung der iatrogenen Recurrenslähmung infolge orthopädisch-gymnastischer Behandlung. Arztliche Wonchenschrift 1957; 12: 428-9.

6 Rustad WH, Morrison LF. Revised anatomy of the recurrent laryngeal nerves. Surgical importance based on the dissection of 100 cadavers. Laryngoscope 1952; 62: 237-49.

7 Asao Y, Takada K, Takabe S, Maeta M, Mashima Y. Vocal cord paralysis following general anesthesia. The Journal of Japan Society for Clinical Anesthesia 1991; 11: 128-31.

8 Hahn FW Jr, Martin JT, Lillie JC. Vocal-cond paralysis with endotracheal intubation. Arch Otolaryng 1970; 92: 226-9.

9 Ellis PDM, Pallister WK. Recurrent laryngeal nerve palsy and endotracheal intubation. J Laryngolgy 1976; 189 : 823-6.

10 Minuck $M$. Unilateral vocal-cord paralysis following endotracheal intubation. Anesthesiology 1976; 45: 448-9.

11 Dobrin P, Canfield T. Cuffed endotracheal tubes: mucosal pressures and tracheal wall blood flow. Am J Surg 1977; 133: $562-8$.

12 Cavo JW Jr. True vocal cord paralysis following intubation. Laryngoscope 1985; 95: 1352-9.

13 Holley HS, Gildea JE. Vocal cord paralysis after tracheal intubation. JAMA 1971; 215: 281-4.

14 Takemoto $K$. Recurrent nerve palsy. Clinical Anesthesia (Japanese) 1980; 4: 705-7.

15 Fujisawa $M$, Ito $S$, Suzuki $M$, et al. Recurrent nerve palsy after endotraheal intubation. Clinical Anesthesia (Japanese) 1980; 4: 708-14.

16 Wangensteen $O H$, Rea $C E$, Smith BA Jr, Schwyzer HC. Experiences with employment of suction in the treatment of acute intestinal obstruction. Surg Gynecol Obstet 1939; 68: 851-68.

17 Iglauer S, Molt WF. Severe injury to the larynx resulting from the indwelling duodenal tube. Ann Otol Rhinol Laryngol 1939; 48: 886-904.

18 Holinger PH, Loeb WJ. Feeding tube stenosis of the larynx. Surg Gynecol Obstet 1946; 83: 253-8.

19 Wolff $A$ P, Kessler $S$. Iatrogenic injury to the hypopharnyx and cervical esophagus. Ann Otol Rhinol Laryngol 1973; 82: 778-83.

20 Holinger LD, Holinger PC, Holinger PH. Etiology of bilateral abductor vocal cord paralysis. Ann Otol Rhinol Laryngol 1976; 85: 428-36.

21 Foster $C A$, Mejerhoff $W L$. Cricoid chondritis. Ear Nose Throat J 1980; 59: 106-9.

22 Canalis RF, Jenkins HA, Osguthorpe JD. Acute laryngeal abscesses. Ann Otol Rhinol Laryngol 1979; 88: 275-9.

23 Clemons JE, Portilla W. Laryngeal abscess. Otolaryngol Head Neck Surg 1979; 87: 339-41.
24 Brandwein M, Abramson AL, Shikowitz MJ. Bilateral vocal cord paralysis following endotracheal intubation. Arch Otolaryngol Head Neck Surg 1986; 112: 877-82.

25 Hollinshead $W H$. Anatomy for Surgeons: Volume 1. The Head and Neck 2nd ed. New York: Harper \& Row Publishers Inc., 1968; 489-90.

26 Takaoka N, Kimura S, Nitta K, Arai T, Takeyoshi S, Senami $M$. Recurrent nerve paralysis following endotracheal anesthesia. Anesthesia and Resuscitation (Japanese) 1981; 17: 213-7. 